\title{
In Vitro Activity of Nicotinamide Adenine Dinucleotide- and Nicotinamide Adenine Dinucleotide Phosphate-linked 15-Hydroxyprostaglandin Dehydrogenases in Placentas from Normotensive and Preeclamptic/Eclamptic Pregnancies
}

\author{
Joseph Jarabak, Jeffry D. Watkins, and Marshall Lindheimer \\ Departments of Medicine and Obstetrics and Gynecology, University of Chicago, Chicago, Illinois 60637
}

\begin{abstract}
Concentrations of prostaglandins $E_{2}$ and $I_{2}$ may be decreased in preeclamptic and eclamptic pregnancies. Because these prostaglandins produce vasodilation and inhibit platelet aggregation it has been suggested that a reduction in their biosynthesis might play an important role in the pathogenesis of the hypertension and coagulation abnormalities associated with preeclampsia. Placental tissue is an extremely rich source of several enzymes that catalyze the catabolism of prostaglandins. The present study was initiated to determine whether one of these catabolic enzymes might be increased in preeclamptic/ eclamptic pregnancies. The activities of the NAD- and the NADP-linked 15-hydroxyprostaglandin dehydrogenases were measured in 16 preeclamptics (mean diastolic pressure, $108 \pm 13 \mathrm{mmHg}$ ) and compared with 16 normotensive controls matched for age $(20.8 \pm 5.43$ vs. $20.6 \pm 5.16)$ and gestational week of delivery $(34.6 \pm 5.40$ vs. $35.0 \pm 5.06)$. These results indicate that the activity of the placental NAD-linked 15-hydroxyprostaglandin dehydrogenase is elevated in preeclampsia (40.1 \pm 31.3 vs. $14.9 \pm 8.30 \mathrm{mU} / \mathrm{g}$ tissue, $P<0.01$ ). If this increase were also expressed in vivo, its effect on prostaglandin metabolism could be mistaken for impaired prostacyclin biosynthesis unless both the 6-keto- and 6,15-diketo-metabolites of prostacyclin were measured.
\end{abstract}

\section{Introduction}

Preeclampsia, a hypertensive disorder peculiar to pregnancy, is accompanied by proteinuria and edema. It may be associated with coagulation abnormalities including increased platelet aggregation. In addition, all of the components of the reninangiotensin-aldosterone system are decreased $(1,2)$. Because of the relationship between prostaglandins and the renin-angiotensin system, Speroff (3) proposed that the development of preeclampsia could represent defective prostaglandin production.

Subsequently a large body of work has suggested that this may, in fact, be so. Initially investigators focused on the possible role of prostaglandins of the E series. Alam et al. (4) dem-

Address reprint requests to Dr. Joseph Jarabak, Department of Medicine, University of Chicago, Box 435, 5841 S. Maryland Ave., Chicago, IL 60637.

Received for publication 11 February 1987 and in revised form 18 May 1987.

\section{J. Clin. Invest.}

(c) The American Society for Clinical Investigation, Inc. 0021-9738/87/10/0936/05 $\$ 2.00$

Volume 80, October 1987, 936-940 onstrated a decreased ability of the placenta to metabolize prostaglandin $\mathrm{E}_{1}\left(\mathrm{PGE}_{1}\right)^{1}$ in individuals with preeclampsia, whereas others $(5,6)$ found decreased concentrations of these prostaglandins in the placenta, amnion, chorion, and decidua of preeclamptic subjects.

More recently attention has shifted to $\mathrm{PGI}_{2}(7)$, an agent that is more effective than $\mathrm{PGE}_{2}$ in causing vasodilation and inhibiting platelet aggregation. Because $\mathbf{P G I}_{2}$ is quite labile, its concentration is measured indirectly, either by determining the concentration of 6-keto $\mathrm{PGF}_{1 \alpha}$ (its stable hydration product) or by bioassay (inhibition of platelet aggregation). Using these methods, decreased "prostacyclin" concentrations have been found in umbilical and placental vasculature (8-13), maternal and umbilical plasma (13), and placental homogenates (14) of preeclamptic subjects.

The discovery that thromboxane $\mathrm{A}_{2}\left(\mathrm{TXA}_{2}\right)$ has physiologic effects opposite those of $\mathrm{PGI}_{2}$ has led to the hypothesis that the concentration of $\mathrm{PGI}_{2}$ relative to the concentration of $\mathrm{TXA}_{2}$ is lower in preeclamptic than in normal pregnancies (15-18). This hypothesis has received some indirect support from studies that have sought to increase the ratio of $\mathrm{PGI}_{2}$ to TXA 2 by $\mathrm{PGI}_{2}$ infusion (19-21) or preferential inhibition (22, 23) of TXA $\mathrm{TX}_{2}$ synthesis by aspirin (16) or by other nonsteroidal antiinflammatory agents (23). In both a retrospective study (24) and randomized, double-blind trial (16), investigators observed that pregnant individuals who took aspirin developed hypertension and proteinuria less frequently than those who did not.

The concentration of endogeneous substances depends not only on the rate of their biosynthesis but also on the rates of their catabolism and clearance. Because the placenta has a much greater capacity to degrade prostaglandins than to synthesize them $(25,26)$, we chose to evaluate the possibility that the placental catabolism of prostaglandins is greater in preeclamptic than in normal subjects.

To do this, we measured the activity of two placental enzymes in preeclamptic and normotensive pregnancies. These enzymes, the NAD-linked (EC 1.1.1.141) and NADP-linked 15-hydroxyprostaglandin dehydrogenases, catalyze the first step in prostaglandin catabolism, oxidation of the 15-hydroxyl group to a ketone. This oxidation results in the biologic inactivation of these compounds (27).

\section{Methods}

16 patients with preeclampsia/eclampsia were studied. The same number of normotensive women with gestational ages comparable with the

1. Abbreviations used in this paper: PG, prostaglandin; TX, thromboxane. 
preeclamptic subjects served as controls. With one exception in each group, all were nulliparous. None had a previous history of hypertension, renal disease, or diabetes mellitus. The patients were selected on the basis of having a normal blood pressure before pregnancy and developing a sustained blood pressure during pregnancy $\geq 140 / 90$ $\mathrm{mmHg}$ or having a sustained systolic $(\geq 30 \mathrm{mmHg})$ and diastolic $(\geq 15$ $\mathrm{mmHg}$ ) rise in pressure. In addition, all subjects displayed proteinuria whereas 14 had edema of the hands and/or face, and two convulsed. All received $\mathrm{Mg}_{2} \mathrm{SO}_{4}$ and 11 were also treated with hydralazine.

All of the placentas were examined grossly, and appropriate sections (containing $<10 \mathrm{~g}$ of tissue) were examined microscopically in the Pathology Laboratory at Chicago Lying-In Hospital. None of the preterm deliveries were due to local infection, fetal death, or disorders that might involve prostaglandins (e.g., hydramnios).

Enzyme assays. Each placenta was chilled immediately after delivery. Within $4 \mathrm{~h}$ of delivery, the villous tissue was thoroughly rinsed in cold tap water, separated from its membranes, and homogenized in 75-g batches at top speed for $2 \mathrm{~min}$ in a Waring blender. Each batch was homogenized in $150 \mathrm{ml}$ of buffer containing $5 \mathrm{mM}$ potassium


fuged at $10,000 \mathrm{~g}$ for $1 \mathrm{~h}$. Both the homogenization and the centrifugation were conducted at $0-4^{\circ} \mathrm{C}$. The supernatant solution was assayed for the NAD- and the NADP-linked hydroxyprostaglandin dehydrogenase activities. The NAD-linked enzyme was assayed as follows: the reaction cuvet $(1.0-\mathrm{cm}$ light path) contained, in a volume of $3.0 \mathrm{ml}$,

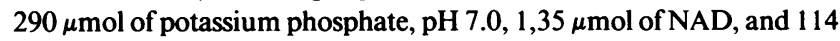
nmol of $\mathrm{PGE}_{1}$ in $0.02 \mathrm{ml}$ of $95 \%$ ethanol. The substrate, but not ethanol, was omitted from the blank. The NADP-linked enzyme was assayed similarly except that $1.08 \mu \mathrm{mol}$ of NADP, and $120 \mathrm{nmol}$ of $\mathrm{PGB}_{1}$ were present instead of $\mathrm{NAD}$ and $\mathrm{PGE}_{1}$. The reactions were initiated by the addition of enzyme. They were run in duplicate at $25 \pm 0.5^{\circ} \mathrm{C}$ in a model 240 recording spectrophotometer (Gilford Instruments Laboratories, Inc., Oberlin, $\mathrm{OH}$ ). Initial reaction rates were determined by measuring the change in absorbance at $340 \mathrm{~nm} .1 \mathrm{U}$ of enzyme activity is defined as the amount of enzyme that catalyzes the reduction of $1 \mu \mathrm{mol}$ of cofactor per min under the conditions of the assay.

Prostaglandins were obtained from the Upjohn Co., Kalamazoo, MI, and pyridine nucleotides from P-L Biochemicals Inc., Milwaukee, WI.

Data are presented as mean and SEM. The two-tailed $t$ test for unpaired data was used for comparison of the data from hypertensive and normotensive subjects.

\section{Results}

Clinical profiles of both preeclamptic/eclamptic and normotensive subjects are summarized in Table I. Mean age $(20.8 \pm 5.43$ vs. $20.6 \pm 5.16 \mathrm{yr})$ and mean duration of gestation (34.6 \pm 5.40 vs. $35.0 \pm 5.06 \mathrm{wk})$ were similar in both groups. There was no difference in the NADP-linked 15-hydroxyprostaglandin dehydrogenase activity per gram tissue between preeclamptic and normal subjects, but the NAD-linked activity was significantly $(P<0.01)$ higher $(40.1 \pm 31.3$ vs. $14.9 \pm 8.30)$ in the preeclamptic subjects. The NAD-linked 15hydroxyprostaglandin dehydrogenase activity did not correlate with the severity of the hypertension, proteinuria, or edema or with the platelet count, uric acid level, or gestational age of the pregnancy.

The presence of $\mathrm{Mg}^{2+}\left(10^{-6}-10^{-1} \mathrm{M}\right)$ in the assay cuvets did not increase the activity of the NAD-linked enzyme that had been isolated from normotensive individuals (data not shown).

Table I. Characteristics and Placental NAD-and NADP-linked 15-Hydroxyprostaglandin Dehydrogenase Activities of Preeclamptic/Eclamptic and of Normotensive Subjects

\begin{tabular}{|c|c|c|c|c|c|c|c|c|c|c|c|c|c|c|c|c|c|}
\hline \multicolumn{9}{|c|}{ Preeclampsia/eclampsia } & \multicolumn{9}{|l|}{ Normal } \\
\hline Subject & Age & $\begin{array}{l}\text { Wk } \\
\text { gestation }\end{array}$ & $\mathrm{G} / \mathrm{P}$ & BP & Edema & $\begin{array}{l}\text { Urine } \\
\text { protein }\end{array}$ & NAD & NADP & Subject & Age & $\begin{array}{l}\text { Wk } \\
\text { gestation }\end{array}$ & $\mathrm{G} / \mathrm{P}$ & BP & Edema & $\begin{array}{l}\text { Urine } \\
\text { protein }\end{array}$ & NAD & NADP \\
\hline & & & & & & & $\begin{array}{l}U / g \\
\times 10^{3}\end{array}$ & $\begin{array}{l}U / g \\
\times 10^{3}\end{array}$ & & & & & & & & $\begin{array}{l}U / g \\
\times 10^{3}\end{array}$ & $\begin{array}{l}U / g \\
\times 10^{3}\end{array}$ \\
\hline $1^{*}$ & 22 & 41 & $1 / 1$ & $130 / 100$ & $1+$ & tr. & 55.4 & 4.32 & 1 & 21 & 41 & $2 / 1$ & $100 / 70$ & 0 & $\operatorname{tr}$ & 22.7 & 1.94 \\
\hline $2^{\ddagger \S}$ & 26 & 26 & $1 / 1$ & $180 / 130$ & $2+$ & $2+$ & 14.5 & 12.6 & 2 & 20 & 26 & $4 / 1$ & $130 / 80$ & - & - & 22.1 & 10.4 \\
\hline 3 & 19 & 37 & $3 / 1$ & $150 / 100$ & $3+$ & $3+$ & 16.6 & 2.18 & 3 & 17 & 38 & $1 / 1$ & $124 / 80$ & $\operatorname{tr}$ & - & 3.65 & 5.55 \\
\hline 4 & 17 & 40 & $2 / 1$ & $164 / 110$ & 0 & $1+$ & 27.5 & 6.61 & 4 & 15 & 40 & $1 / 1$ & $110 / 76$ & 0 & 0 & 16.2 & 9.40 \\
\hline 5 & 13 & 37 & $1 / 1$ & $140 / 100$ & 0 & $2+$ & 85.5 & 9.61 & 5 & 17 & 38 & $1 / 1$ & $110 / 70$ & 0 & - & 10.8 & 6.94 \\
\hline 6 & 27 & 40 & $1 / 1$ & $190 / 130$ & $\operatorname{tr}$ & $2+$ & 21.8 & 6.54 & 6 & 23 & 40 & $2 / 1$ & $110 / 70$ & 0 & $1+$ & 19.1 & 4.36 \\
\hline 7 & 14 & 36 & $1 / 1$ & $170 / 110$ & $2+$ & $2+$ & 125 & 17.1 & 7 & 33 & 37 & $2 / 1$ & $110 / 80$ & 0 & 0 & 18.4 & 4.10 \\
\hline $8^{*}$ & 23 & 36 & $2 / 2$ & $220 / 120$ & $2+$ & $3+$ & 10.7 & 6.45 & 8 & 22 & 36 & $1 / 1$ & $110 / 70$ & 0 & $1+$ & 9.42 & 6.10 \\
\hline $9^{\ddagger}$ & 17 & 36 & $1 / 1$ & $180 / 108$ & $1+$ & $2+$ & 27.2 & 6.54 & 9 & 17 & 35 & $2 / 1$ & $124 / 79$ & 0 & 0 & 9.88 & 6.04 \\
\hline $10^{*}$ & 25 & 40 & $2 / 1$ & $150 / 90$ & $1+$ & $2+$ & 14.5 & 2.89 & 10 & 16 & 40 & $2 / 1$ & $130 / 80$ & 0 & 0 & 7.68 & 2.74 \\
\hline $11^{* \|}$ & 28 & 39 & $1 / 1$ & $140 / 90$ & $1+$ & $3+$ & 44.8 & 12.4 & 11 & 18 & 39 & $1 / 1$ & $120 / 80$ & 0 & 0 & 29.0 & 12.75 \\
\hline $12^{* \S}$ & 20 & 29 & $2 / 1$ & $180 / 120$ & $2+$ & $3+$ & 40.3 & 16.1 & 12 & 31 & 29 & $7 / 2$ & $118 / 70$ & - & - & 2.33 & 2.74 \\
\hline 13 & 31 & 23 & $2 / 1$ & $175 / 95$ & $1+$ & $3+$ & 34.8 & 3.48 & 13 & 24 & 26 & $1 / 1$ & $110 / 60$ & 0 & 0 & 10.0 & 4.00 \\
\hline $14^{*}$ & 20 & 31 & $1 / 1$ & $170 / 100$ & $1+$ & $4+$ & 70.0 & 2.30 & 14 & 21 & 31 & $1 / 1$ & $120 / 80$ & 0 & - & 15.5 & 12.3 \\
\hline $15^{* \neq}$ & 16 & 31 & $1 / 1$ & $150 / 110$ & $1+$ & $4+$ & 40.0 & 9.10 & 15 & 17 & 31 & $1 / 1$ & $118 / 70$ & 0 & 0 & 11.7 & 8.17 \\
\hline $16^{*}$ & 15 & 32 & $1 / 1$ & $150 / 120$ & $2+$ & $4+$ & 11.1 & 4.50 & 16 & 18 & 33 & $1 / 1$ & $120 / 80$ & 0 & - & 30.6 & 9.30 \\
\hline Mean & 20.8 & 34.6 & & $165 / 108$ & & & 40.1 & 7.67 & Mean & 20.6 & 35.0 & & $117 / 75$ & & & 14.9 & 6.66 \\
\hline SEM & 5.43 & 5.40 & & $23 / 13$ & & & 31.3 & 4.75 & SEM & 5.16 & 5.06 & & $8 / 6$ & & & 8.30 & 3.37 \\
\hline
\end{tabular}

Preeclampsia/eclampsia vs. normotensive subjects: NAD-linked activity $(P<0.01)$, NADP-linked activity $\left(P=\right.$ NS). $\quad{ }^{*}$ Uric acid $>5.0$ $\mathrm{mg} /$ dl. ${ }^{\ddagger}$ Platelets $<100,000$. ${ }^{\S}$ Convulsed. " Platelets $<150,000$. 


\section{Discussion}

Observations of decreased production and/or concentration of the vasodilatory prostaglandins in preeclampsia have led to speculation that this decrement may play a role in the pathogenesis of the disease. Investigators noting decreased $\mathrm{PGE}_{2}$ or $\mathrm{PGI}_{2}$ concentrations have generally assumed that these were synonymous with decreased $\mathrm{PGE}_{2}$ or $\mathrm{PGI}_{2}$ biosynthesis. This assumption has proved difficult to establish rigorously because of the rapid metabolism of prostaglandins, the generation of prostaglandins by platelets $(28)$, and the inherent instability of $\mathrm{PGI}_{2}$ (29). In an attempt to eliminate these potential artifacts, two experimental approaches have been taken. Metabolites of prostaglandins which have a long biological half-life have been measured or prostaglandin biosynthesis has been examined in vitro. The study by Goodman et al. (30) is an example of the first approach. This group investigated $\mathrm{PGI}_{2}$ biosynthesis during pregnancy by measuring urinary excretion of 2,3-dinor-6keto prostaglandin $\mathrm{F}_{1 \alpha}$ and 15-keto-13,14-dihydro-2,3-dinor6-keto prostaglandin $F_{1 \alpha}$. They found that the excretion of both of these metabolites was less during a preeclamptic pregnancy than during a normotensive pregnancy, and they concluded that there is less $\mathbf{P G I}_{2}$ biosynthesis during a preeclamptic pregnancy than during a normotensive one. A potential weakness of such an approach results from the fact that it does not measure all of the metabolites of the parent compound. Under those circumstances, alterations in the metabolism of the parent compound or the clearance of its metabolites could be interpreted incorrectly as revealing a decrease in the biosynthesis of the parent compound. Walsh et al. took the second approach (14). They examined $\mathrm{PGI}_{2}$ biosynthesis in vitro, demonstrated that the concentration of 6-keto $\mathrm{PGF}_{1 \alpha}$ increased less rapidly in minced placental specimens from preeclamptic pregnancies than from normal pregnancies, and reached the same conclusion as Goodman et al. Although the observations made in both experimental approaches are consistent with the hypothesis that prostacyclin production is reduced in preeclampsia, they do not exclude other interpretations, e.g., that prostaglandin catabolism is increased in some cases of preeclampsia.

Furthermore, attempts to establish the nature of the defect in prostacyclin biosynthesis have been disappointing. Despite the earlier observation that arachidonic acid levels are lower in placentas from preeclamptic pregnancies than in those from normal pregnancies (31), the addition of arachidonic acid to minced placental specimens did not affect the rate at which 6-keto $\mathrm{PGF}_{1 \alpha}$ accumulated (14). This led Walsh et al. to conclude: "precursor availability is not a limiting factor and cannot account for the difference in prostacyclin production by normal and toxemic placentas" (14). Kreise et al. used monoclonal antibodies to measure the uterine enzymes involved in prostacyclin synthesis (the prostacyclin synthase and the prostaglandin endoperoxide synthase) and found that the concentrations of these enzymes did not differ between subjects with severe preeclampsia and those with normal blood pressures (32).

The findings outlined in the two preceding paragraphs raise the possibility that there are alternative or additional explanations to account for the decreased $\mathrm{PGE}_{2}$ or $\mathrm{PGI}_{2}$ concentrations in placentas from preeclamptic pregnancies. The results of the present study suggest such an explanation in at least some instances: the activity of the first enzyme in the pathway of prostaglandin catabolism, the NAD-linked 15-hydroxyprostaglandin dehydrogenase, is significantly higher in placentas obtained from subjects with preeclampsia/eclampsia than in those obtained from subjects who are normotensive.

Placental tissue contains an NAD-linked and an NADPlinked enzyme with 15-hydroxyprostaglandin dehydrogenase activity $(25,33)$. The NAD-linked enzyme catalyzes the 15 oxidation of $\mathrm{PGI}_{2}$ as well as $\mathrm{PGE}_{2}(34)$. A similar enzymatic oxidation of $\mathrm{PGI}_{2}$ has been demonstrated to occur in blood vessels (35), lung (36), and kidney (37) but it is not clear whether a single enzyme catalyzes these reactions. Extensive structure-activity studies have demonstrated that the NADlinked enzyme has a greater catalytic efficiency $\left(\mathrm{k}_{\mathrm{cat}} / K_{\mathrm{m}}\right)$ for prostaglandins than for other compounds, whereas the NADP-linked enzyme is a less specific carbonyl reductase (38). In this light it is noteworthy that we have observed a significant increase in only the NAD-linked activity in placentas from preeclamptic/eclamptic pregnancies.

Kinetic studies on the NAD-linked enzyme reveal that its $K_{\mathrm{m}}$ for $\mathrm{PGE}_{2}$ and NAD at pH 7.0 are $2.5 \mu \mathrm{M}$ and $28.4 \mu \mathrm{M}$, respectively (39). Placental tissue contains enough of the NAD-linked enzyme to oxidize at least 1,000 times more $\mathrm{PGE}_{2}, \mathrm{PGF}_{2 \alpha}$, and $\mathrm{PGI}_{2}$ than is synthesized daily in pregnancy if there were no compartmentation and if the concentrations of cofactor and substrate were saturating. This is not the case physiologically and undoubtedly explains why the oxidation of prostaglandins by disrupted placental tissue is greater when both substrate and cofactor are saturating $(26,34)$ than when no cofactor is added $(4,40,41)$ or during pregnancy when the placenta is intact and both substrate and cofactor are at physiologic concentrations $(30,42)$. Although we used concentrations of reactants that are higher than those present physiologically, we chose these conditions because they yield zero-order enzyme kinetics. Under such conditions the initial reaction velocity is proportional to the amount of enzyme present (or, more strictly speaking, it is proportional to the catalytic efficiency of the enzyme), and it is independent of variations in substrate or cofactor concentration. At present we do not know whether the increased activity of the NAD-linked enzyme represents an activation of the enzyme, more enzyme, or both.

Recently Watson et al. (43) noted that $\mathrm{Mg}_{2} \mathrm{SO}_{4}$ enhances $\mathrm{PGI}_{2}$ released by cultured human umbilical vein endothelial cells. In the present study we found that $\mathrm{Mg}^{2+}$, in concentrations similar to those achieved during therapeutic $\mathrm{Mg}_{2} \mathrm{SO}_{4}$ infusions, has no effect on the activity of the NAD-linked 15-hydroxyprostaglandin dehydrogenase in vitro.

Although our results were obtained in vitro, their relevance to in vivo observations merits comment. Under appropriate circumstances increased activity of the NAD-linked 15-hydroxyprostaglandin dehydrogenase would increase the rate of $\mathrm{PGI}_{2}$ and 6-keto $\mathrm{PGF}_{1 \alpha}$ oxidation in the placenta, resulting in reduced concentrations of these compounds and increased concentrations of their products, 15-keto $\mathrm{PGI}_{2}$ and 6,15-diketo $\mathrm{PGF}_{1 \alpha}$. This ultimately would cause decreased excretion of some $\mathrm{PGI}_{2}$ metabolites (e.g., 6-keto $\mathrm{PGF}_{1 \alpha}$ and 6-keto-2,3dinor $\mathrm{PGF}_{1 \alpha}$ ) and increased excretion of others (e.g., 6,15-diketo-13,14-dihydro $\mathrm{PGF}_{1 \alpha}$ and 6,15-diketo-13,14-dihydro2,3-dinor $\mathrm{PGF}_{1 \alpha}$ ). Whereas decreased excretion of 6-keto $\mathrm{PGF}_{1 \alpha}$ has been demonstrated in a number of studies of preeclamptic pregnancies, only Goodman et al. (30) have used gas 
chromatography-mass spectroscopy to address the issue of whether this alteration is due solely to decreased prostacyclin biosynthesis. They measured the urinary excretion of 6-keto2,3-dinor $\mathrm{PGF}_{1 \alpha}$ and 6,15-diketo-13,14-dihydro-2,3-dinor $\mathrm{PGF}_{1 \alpha}$ in preeclamptic and normotensive pregnancies. The excretion of both compounds was lower in preeclamptic than in normotensive pregnancies, but there was no difference in the ratio of the 6,15-diketo- to the 6-keto-compound when the two groups ( $n=5$ in both groups) were compared.

The results of the present study indicate that the activity of the placental NAD-linked 15-hydroxyprostaglandin dehydrogenase is elevated in preeclamptic pregnancies. If this in vitro increase in enzyme activity were also expressed in vivo, one consequence would be to alter the excretion of 6-keto $\mathrm{PGF}_{1 \alpha}$ in such a way to suggest impaired prostacyclin biosynthesis. Thus prostaglandin catabolism may have contributed to findings previously attributed solely to prostacyclin production. Although the most rigorous study of prostacyclin metabolism in preeclampsia (30) has not shown an increase in prostacyclin catabolism, the importance of this issue from an etiologic and a therapeutic standpoint and the limited number of observations specifically dealing with it suggest the need for future studies to directly assess the contribution of prostacyclin catabolism to the genesis of decreased 6-keto $\mathrm{PGF}_{1 \alpha}$ in preeclampsia. This will require the measurement of both the 6-keto- and 6,15-diketo-metabolites of prostacyclin if in vivo studies are performed.

\section{Acknowledgments}

The authors express their appreciation to Dr. A. Moawad and A. Talerman and their staffs for their help in obtaining and histologically examining the tissues used in this study. We also gratefully acknowledge the valuable assistance of Dr. T. Karrison in the statistical analysis of the data.

This study was supported by grant HD-07045 from the National Institutes of Health.

\section{References}

1. Weir, R. J., R. Fraser, A. F. Lever, J. J. Morton, J. J. Brown, A. Kraszewski, G. M. Mcllwaine, and J. I. S. Robertson. 1973. Plasma renin, renin substrate, angiotensin II, and aldosterone in hypertensive disease of pregnancy. Lancet. i:291-294.

2. Aalkjaer, C., H. Danielsen, P. Johannesen, E. B. Pedersen, A. Rasmussen, and M. J. Mulvany. 1985. Abnormal vascular function and morphology in preeclampsia: a study of isolated resistance vessels. Clin. Sci. 69:477-482.

3. Speroff, L. 1973. An essay: prostaglandins and toxemia of pregnancy. Prostaglandins. 3:721-728.

4. Alam, N. A., P. Clary, and P. T. Russell. 1973. Depressed prostaglandin $\mathrm{E}_{1}$ metabolism in toxemia of pregnancy. Prostaglandins. 4:363-370.

5. Demers, L. M., and S. G. Gabbe. 1976. Placental prostaglandin levels in pre-eclampsia. Am. J. Obstet. Gynecol. 126:137-139.

6. Robinson, J. S., C. W. G. Redman, L. Clover, and M. D. Mitchell. 1979. The concentrations of the prostaglandin $E$ and F, 13,14-dihydro-15-oxo-prostaglandin $F$ and thromboxane $B_{2}$ in tissues obtained from women with and without pre-eclampsia. Prostaglandins and Medicine. 3:223-234.

7. Remuzzi, G., R. Misiani, D. Muratore, D. Marchesi, M. Livio, A. Schieppati, G. Mecca, G. de Gaetano, and M. B. Donati. 1979. Prostacyclin and human fetal circulation. Prostaglandins. 18:341-348.

8. Remuzzi, G., D. Marchese, G. Mecca, R. Misiani, E. Rossi,
M. B. Donati, and G. de Gaetano. 1980. Reduction of fetal vascular prostacyclin activity in pre-eclampsia. Lancet. i:310.

9. Carreras, I. O., G. Defreyn, E. van Houtte, J. Vermylen, and A. van Assche. 1981. Prostacyclin and pre-eclampsia. Lancet. i:442.

10. Downing, I., G. L. Shepherd, and P. J. Lewis. 1982. Reduced prostacyclin production in pre-eclampsia. Lancet. ii:1374.

11. Remuzzi, G., D. Marchesi, C. Zoja, D. Muratore, G. Mecca, R. Misiani, E. Rossi, M. Barbato, P. Capetta, M. B. Donati, and G. de Gaetano. 1980. Reduced umbilical and placental vascular prostacyclin in severe pre-eclampsia. Prostaglandins. 20:105-110.

12. Makila, U.-M., L. Viinikka, and O. Ylikorkala. 1984. Evidence that prostacyclin deficiency is a specific feature in preeclampsia. $\mathrm{Am}$. J. Obstet. Gynecol. 148:772-774.

13. Yamaguchi, $M$., and N. Mori. 1985. 6-Keto prostaglandin $F_{1 \alpha}$ thromboxane $B_{2}$, and 13,14-dihydro-15-keto prostaglandin $F$ concentrations of normotensive and preeclampsia patients during pregnancy, delivery, and the post partum period. Am. J. Obstet. Gynecol. 151:121-127.

14. Walsh, W. S., M. J. Behr, and N. H. Allen. 1985. Placental prostacyclin production in normal and toxemic pregnancies. Am. J. Obstet. Gynecol. 151:110-115.

15. Makila, U.-M., L. Viinikka, and O. Ylikorkala. 1984. Increased thromboxane $\mathrm{A}_{2}$ production but normal prostacyclin by the placenta in hypertensive pregnancies. Prostaglandins. 27:87-95.

16. Wallenburg, H. C. S., G. A. Dekker, J. W. Makovitz, and P. Rotmans. 1986. Low-dose aspirin prevents pregnancy-induced hypertension and pre-eclampsia in angiotensin-sensitive primigravidae. Lancet. i:1-3.

17. Van Assche, F. A., B. Spitz, J. Vermylen, and H. Deckmijn. 1984. Preliminary observations on treatment of pregnancy-induced hypertension with a thromboxane synthetase inhibitor. Am. J. Obstet. Gynecol. 148:216-218.

18. Walsh, S. W. 1985. Preeclampsia: an imbalance in placental prostacyclin and thromboxane production. Am. J. Obstet. Gynecol. 152:335-340.

19. Fidler, J., M. J. Bennett, M. de Swiet, C. Ellis, and P. J. Lewis. 1980. Treatment of pregnancy hypertension with prostacyclin. Lancet. i:31-32.

20. Ylikorkala, O., and U.-M. Makila. 1985. Prostacyclin and thromboxane in gynecology and obstetrics. Am. J. Obstet. Gynecol. 152:318-329.

21. Lewis, P. J., G. L. Shepherd, J. Ritter, S. M. T. Chan, P. J. Bolton, M. Jogee, L. Myatt, and M. G. Elder. 1981. Prostacyclin and pre-eclampsia. Lancet. i:559.

22. Masotti, G., L. Poggesi, G. Galanti, R. Abbate, and G. G. Neri Serneri. 1979. Differential inhibition of prostacyclin production and platelet aggregation by aspirin. Lancet. ii:1213-1216.

23. Malkila, U.-M., E. Kokkonen, L. Viinikka, and O. Ylikorkala. 1983. Differential inhibition of fetal vascular prostacyclin and platelet thromboxane synthesis by nonsteroidal anti-inflammatory drugs in humans. Prostaglandins. 25:39-46.

24. Crandon, A. J., and D. M. Isherwood. 1979. Effect of aspirin on incidence of pre-eclampsia. Lancet. ii:1356.

25. Jarabak, J. 1972. Human placental 15-hydroxyprostaglandin dehydrogenase. Proc. Natl. Acad. Sci. USA. 69:533-534.

26. Jarabak, J. 1980. Early steps in prostaglandin metabolism in the human placenta. Am. J. Obstet. Gynecol. 138:534-540.

27. Anggard, E. 1966. The biological activities of three metabolites of prostaglandin $\mathrm{E}_{1}$. Acta. Physiol. Scand. 66:509-510.

28. Samuelsson, B. 1972. Quantitative aspects on prostaglandin synthesis in man. Adv. Biosci. 9:7-14.

29. Cho, M. J., and M. A. Allen. 1978. Chemical stability of prostacyclin $\left(\mathrm{PGI}_{2}\right)$ in aqueous solutions. Prostaglandins. 15:943-954.

30. Goodman, R. T., A. P. Killam, A. R. Brash, and R. A. Branch. 1982. Prostacyclin production during pregnancy: comparison of production during normal pregnancy and pregnancy complicated by hypertension. Am. J. Obstet. Gynecol. 142:817-822. 
31. Ogburn, P. L., P. P. Williams, S. B. Johnson, and R. T. Holman. 1984. Serum arachidonic acid levels in normal and preeclamptic pregnancies. Am. J. Obstet. Gynecol. 148:5-9.

32. Keirse, M. J. N. C., P. Moonen, and G. Klok. 1985. Control of prostacyclin synthesis in pregnancy-induced hypertension. Prostaglandins. 29:643-650.

33. Westbrook, C., Y.-M. Lin, and J. Jarabak. 1977. NADP-linked 15-hydroxyprostaglandin dehydrogenase from human placenta: partial purification and characterization of the enzyme and identification of an inhibitor in placental tissue. Biochem. Biophys. Res. Commun. 76:943-949.

34. Jarabak, J., and J. Fried. 1979. Comparison of substrate specificities of the human placental NAD- and NADP-linked 15-hydroxyprostaglandin dehydrogenases. Prostaglandins. 18:241-246.

35. Wong, P. Y.-K., F. F. Sun, and J. C. McGiff. 1978. Metabolism of prostacyclin in blood vessels. J. Biol. Chem. 253:5555-5557.

36. McGuire, J. C., and F. F. Sun. 1978. Metabolism of prostacyclin: oxidation by rhesus monkey lung 15 -hydroxyl prostaglandin dehydrogenase. Arch. Biochem. Biophys. 189:92-96.

37. Wong, P. Y.-K., J. C. McGiff, L. Cagen, K. U. Malik, and F. F. Sun. 1979. Metabolism of prostacyclin in the rabbit kidney. J. Biol. Chem. 254:12-14.
38. Jarabak, J., A. Luncsford, and D. Berkowitz. 1983. Substrate specificity of three prostaglandin dehydrogenases. Prostaglandins. 26:849-868.

39. Jarabak, J., and S. S. Braithwaite. 1976. Kinetic studies on a 15-hydroxyprostaglandin dehydrogenase from human placenta: the reaction mechanism and mechanism of action of various inhibitors. Arch. Biochem. Biophys. 177:245-254.

40. Keirse, M. J. N. C., M. C. A. J. A. Hanssens, B. R. Hicks, and A. C. Turnbull. 1976. Prostaglandin metabolism in placenta and chorion before and after the onset of labor. Eur. J. Obstet. Gynecol. Reprod. Biol. 6:1-6.

41. Ekblad, U., R. Erkkola, and P. Uotila. 1982. Prostaglandin $E_{2}$ is only slightly metabolized in the fetal circulation of perfused human placenta. Prostaglandins Leukotrienes Med. 8:481-488.

42. Hamberg, M. 1974. Quantitative studies on prostaglandin synthesis in man. III. Excretion of the major urinary metabolite of prostaglandins $F_{1 \alpha}$ and $F_{2 \alpha}$ during pregnancy. Life Sci. 14:247-252.

43. Watson, K. V., C. F. Moldow, P. L. Ogburn, and H. S. Jacob. 1986. Magnesium sulfate: rationale for its use in preeclampsia. Proc. Natl. Acad. Sci. USA. 83:1075-1078. 